\title{
Pilot Study of a Brief WeChat Intervention in China to Increase Students'Willingness to Assist a Flushing Student to Reduce Alcohol Use
}

\author{
Fan Zhang' ${ }^{1}$ Lok-Wa Yuen², Lanyan Ding' ${ }^{2}$ Ian M. Newman², Duane F. Shell ${ }^{2}$ \\ ${ }^{1}$ Department of Epidemiology, School of Public Health and Management, Chongqing Medical University, Chongqing, China; ${ }^{2}$ Nebraska Prevention \\ Center for Alcohol and Drug Abuse, Department of Educational Psychology, University of Nebraska-Lincoln, Lincoln, NE, USA
}

Objectives: This pilot study tested the effectiveness of a brief alcohol-related intervention delivered by the social media app WeChat to teach about ethanol-induced facial flushing and increase the willingness of students who see another student flushing to suggest that he or she should reduce or stop drinking. In the context of Chinese drinking culture, it is sometimes socially difficult to refuse a drink, even when experiencing physical discomfort, such as flushing.

Methods: Classrooms of students in a medical university in China were randomly assigned to the intervention or control group. Students in the intervention group were invited to view 3 alcohol education lessons on WeChat during a 2-week period. A pretest and posttest before and after the 2-week period assessed changes in students' willingness to intervene if they saw someone flush while drinking. Data were collected about students' alcohol use and their ratings of the lessons.

Results: Mixed-design analysis of variance yielded a significant time-by-treatment interaction effect on the variable of willingness to suggest that a flushing person stop or slow down their drinking, and the change was significant between the intervention and control groups. One-way analysis of covariance yielded a significant treatment effect at the posttest, after controlling for the pretest score. Students rated the lessons above the midpoint of the scale for being informative, interesting, and useful.

Conclusions: The pilot study showed that a brief alcohol-related intervention delivered by WeChat could produce a measurable positive change in the willingness of university students to suggest that a student who flushes should stop drinking. This pilot study also suggested improvements for future lessons and evaluation design.

Key words: University students, Aldehyde dehydrogenase, Acetaldehyde, Cancer prevention, Ethanol

\section{INTRODUCTION}

Received: June 5, 2018 Accepted: October 29, 2018

Corresponding author: lan M. Newman, PhD

Nebraska Prevention Center for Alcohol and Drug Abuse, Department of Educational Psychology, University of Nebraska-Lincoln, P.O. Box 880345, Lincoln, NE 68588-0345, USA

E-mail: inewman1@unl.edu

This is an Open Access article distributed under the terms of the Creative Commons Attribution Non-Commercial License (http://creativecommons.org/licenses/by$\mathrm{nc} / 4.0 /$ ) which permits unrestricted non-commercial use, distribution, and reproduction in any medium, provided the original work is properly cited.
One-third to one-half of Asians do not metabolize alcohol efficiently. Complete metabolism occurs when alcohol (ethanol) is converted to acetaldehyde by alcohol dehydrogenase, and then finally converted to acetate by aldehyde dehydrogenase [1]. When alcohol is incompletely metabolized, acetaldehyde accumulates in the body, resulting in physical discomfort [2] and an increased risk for aerodigestive cancers [3]. Individuals lacking the enzymes needed to metabolize alcohol effi- 
ciently often flush red in the face and neck when drinking - a visible sign to other people of the individual's cancer risk. As such, flushing presents a unique opportunity for other people to encourage the flushing drinker to stop or reduce their drinking.

Most drinkers in China drink together in social settings for reasons such as friendship, hospitality, and loyalty [4]. In this context, it is not polite to discourage someone from drinking. In many situations, it is almost impossible to refuse an offered drink without insulting someone; thus, it is difficult for people who experience ethanol-induced flushing to stop or reduce their drinking [5-8].

Surveys have suggested that the majority of Chinese college students do not know the cause of facial flushing [5-8]. Logically, if we could increase awareness of the cause of ethanolinduced flushing and the increased cancer risk, we might reduce the social pressure to drink for students who flush. We surmised that for university students, education about flushing might be possible and effective using smartphones, considering that $94.0 \%$ of the Chinese population in 2016 aged 18 to 34 owned a smartphone [9], and $95.1 \%$ of Internet users accessed the Internet with a mobile device [10].

Messages via smartphones must be brief. Research suggests that brief educational messages delivered by social media can positively change people's health behaviors and intentions [11-13] and have been effective in reducing high-risk drinking harms among US college students [14-17]. Systematic reviews have reported positive outcomes of mobile-device delivery of health behavior messages $[18,19]$, and students who used social media educational messages rated them as a positive learning experience [13].

In light of these findings, we developed a brief, WeChatbased, 3-lesson intervention with 3 objectives: (1) increasing knowledge of the cause of facial flushing and the associated risks, (2) helping participants identify situations in which it is socially acceptable to excuse someone from drinking $[7,8]$, and (3) suggesting that people encourage flushers to reduce or stop their drinking and discourage others from pushing flushers to drink more. Each objective was the topic of 1 lesson. The lessons were brief (about 3 or 4 minutes). The WeChat lessons were posted one at a time on the first 3 days of the 2 -week time period. Students could log on at any time during the 2 weeks to read the lessons and could repeat any of the lessons.

This paper describes the pilot test of this program with Chi- nese university medical students. The dependent variable for this pilot test was students' willingness to suggest that a flushing student stop or reduce his or her drinking.

\section{METHODS}

\section{Setting and Participants}

A pretest/posttest, intervention-control group design was used to evaluate this pilot program. Undergraduate students taking introductory medicine courses at a medical university in China were sampled. Classrooms of students meeting at the same time were randomly assigned to either the intervention group or the control group. Students in the intervention group were invited to access the 3 lessons on WeChat in the 2-week project period. Students in both groups completed a short pretest questionnaire and, 2 weeks later, a short posttest. All students present on that day completed the tests. The pretest and posttest questions asked students about their willingness to intervene in 4 drinking situations: when the flusher was their classmate, when the flusher was male, when the flusher was female, and their willingness to encourage others in a drinking group to not pressure a flushing student to keep drinking. Willingness was assessed on a 10-point Likert scale ranging from "very unlikely" (1) to "very likely" (10). The mean change in willingness from pretest to posttest was the dependent variable.

To be included in the intervention group, students had to complete the pretest, open at least 1 of the 3 WeChat lessons, and complete the posttest. At the posttest, they were asked to evaluate how informative, interesting, and useful the lessons were on a 10-point Likert scale ranging from "not very"(1) to "very" (10).

The pretest also collected the students' ID number, demographic information, drinking status, and whether or not the student flushed. The pretest and posttest were completed in classrooms under examination conditions.

The institutional review board of the University of NebraskaLincoln approved the study (\#20180517816 EX).

\section{Statistical Analysis}

Only students who completed both the pretest and posttest were included in the analysis. For the intervention group, students had to have opened at least 1 lesson.

Mixed-design analysis of variance (ANOVA) was used to examine students' willingness to encourage a flushing drinker to 
reduce or stop drinking. In this analysis, the control/intervention group (treatment) was considered a between-subject factor and the pretest/posttest (time) was considered a withinsubject factor. The time-by-treatment interaction was included to test whether the mean change in willingness from pretest to posttest would differ between the control and the intervention group.

Additionally, analysis of covariance (ANCOVA) was used to examine the posttest scores for willingness to intervene. In the model, the control/intervention group (treatment) was an independent variable, and the pretest score was a covariate to test whether the posttest means would differ between the control and intervention groups, adjusted for the pretest score.

\section{RESULTS}

\section{Sample Description}

In all, 1650 students were invited to participate in the project: 1127 in the intervention group and 523 in the control group. Of the 1127 intervention group students, 870 completed the pretest, and 418 also completed the posttest and read at least 1 lesson. Of the 523 students in the control group, 442 completed the pretest and 334 also completed the posttest. This project evaluation was based on the test results of these 418 intervention students and the 334 control students.

Table 1 shows that there was a sex difference in the inter- vention group between students who completed the pretest and posttest and read at least 1 lesson and those who did not. Females were more likely not to complete the program than males. There was no significant difference in the intervention group in drinking patterns and flushing incidence between those who completed the required tasks and those who did not. Among the students in the control group there were no major and consistent differences among those who completed the pretest and posttest and those who did not.

Table 2 provides the mean scores for students' willingness to suggest that someone who flushes should stop drinking. The intervention group had a moderate increase in scores from the pretest to posttest, while the scores of the students in the control group remained almost the same from the pretest to posttest.

\section{Mixed-design Analysis of Variance}

Mixed-design ANOVA yielded a significant time-by-treatment interaction effect on willingness to intervene when the flusher was their classmate $(F[1,750], 14.21 ; p<0.001)$, when the flusher was a male $(F[1,750], 14.15 ; p<0.001)$, when the flusher was a female $(F[1,750], 28.00 ; p<0.001)$, and for encouraging others not to pressure a flusher to continue drinking $(F[1,750], 13.24 ; p<0.001)$. These results indicate the changes in willingness were significantly different between the control and intervention groups in all of the 4 given situations, suggesting that the difference was related to the We-

Table 1. Demographic comparison of students who completed and who did not complete the required tasks for inclusion in the analysis of the brief alcohol-related intervention

\begin{tabular}{|c|c|c|c|c|c|c|}
\hline & \multicolumn{2}{|c|}{ Intervention $^{1}$} & \multirow{2}{*}{$\underset{\text { (p-value) }}{\chi^{2}}$} & \multicolumn{2}{|c|}{ Control $^{2}$} & \multirow{2}{*}{$\underset{(\boldsymbol{p} \text {-value })}{\chi^{2}}$} \\
\hline & Complete & Incomplete & & Complete & Incomplete & \\
\hline Total & 418 & 452 & & 334 & 108 & \\
\hline \multicolumn{7}{|l|}{$\operatorname{Sex}^{3}$} \\
\hline Male & $118(40.3)$ & $175(59.7)$ & $10.85(0.001)$ & $118(76.1)$ & $37(23.9)$ & $0.04(0.84)$ \\
\hline Female & $300(52.1)$ & $276(47.9)$ & & $216(75.3)$ & $71(24.7)$ & \\
\hline \multicolumn{7}{|c|}{ Drinking in the last $30 \mathrm{~d}$} \\
\hline Yes & $94(46.1)$ & $110(53.9)$ & $0.41(0.52)$ & $93(78.1)$ & $26(21.8)$ & $0.59(0.44)$ \\
\hline No & $324(48.6)$ & $342(51.3)$ & & $241(74.6)$ & $82(25.4)$ & \\
\hline \multicolumn{7}{|c|}{ Do you flush?4 } \\
\hline Yes & $199(47.6)$ & 193 (49.2) & $2.13(0.15)$ & $160(79.2)$ & 42 (20.8) & $2.67(0.10)$ \\
\hline No & $216(51.7)$ & $257(53.3)$ & & $174(72.5)$ & $66(27.5)$ & \\
\hline
\end{tabular}

Values are presented as number (\%).

${ }^{1}$ Intervention group: completed pretest and posttest and opened at least 1 lesson on WeChat.

${ }^{2}$ Control group: completed pretest and posttest.

${ }^{3}$ One person in the intervention group did not report sex.

${ }^{4}$ Three people did not report whether they flushed. 
Table 2. Descriptive summary of students' willingness to intervene in 4 situations: means of a 10-point scale

\begin{tabular}{|c|c|c|c|c|c|}
\hline Treatment group ${ }^{2}$ & Time & $\begin{array}{l}\text { Suggest that a classmate } \\
\text { stop/reduce }\end{array}$ & $\begin{array}{l}\text { Suggest that a male } \\
\text { flusher stop/reduce }\end{array}$ & $\begin{array}{l}\text { Suggest that a female } \\
\text { flusher stop/reduce }\end{array}$ & $\begin{array}{l}\text { Suggest not to pressure } \\
\text { a flusher to drink more }\end{array}$ \\
\hline \multirow[t]{2}{*}{ Intervention ( $\mathrm{n}=418$ ) } & Pre & $6.03 \pm 2.70$ & $5.12 \pm 2.69$ & $7.68 \pm 2.37$ & $6.33 \pm 2.54$ \\
\hline & Post & $6.84 \pm 2.31$ & $6.19 \pm 2.40$ & $8.15 \pm 1.98$ & $6.98 \pm 2.15$ \\
\hline \multirow[t]{2}{*}{ Control $(n=334)$} & Pre & $6.31 \pm 2.76$ & $5.36 \pm 2.76$ & $7.94 \pm 2.34$ & $6.40 \pm 2.47$ \\
\hline & Post & $6.42 \pm 2.52$ & $5.73 \pm 2.51$ & $7.52 \pm 2.46$ & $6.39 \pm 2.37$ \\
\hline
\end{tabular}

Values are presented as mean \pm standard deviation.

'Ranging from "very unlikely" (1) to "very likely" (10).

${ }^{2}$ Based on the test results of these 418 intervention students and the 334 control students

Table 3. Estimated marginal mean differences in students' willingness to intervene by treatment condition (control vs. intervention) ${ }^{1}$

\begin{tabular}{lccc}
\hline \multirow{2}{*}{ Situation } & $\begin{array}{c}\text { Intervention } \\
\text { effect }^{* * *}\end{array}$ & \multicolumn{2}{c}{$\mathbf{9 5 \%} \mathbf{~ C l ~}$} \\
\cline { 3 - 5 } & & $\mathbf{L L}$ & $\mathbf{U L}$ \\
\hline Suggest that a classmate stop/reduce & 0.55 & 0.25 & 0.85 \\
Suggest that a male flusher stop/reduce & 0.57 & 0.27 & 0.87 \\
Suggest that a female flusher stop/reduce & 0.75 & 0.48 & 1.03 \\
$\begin{array}{l}\text { Suggest that others not pressure a flusher } \\
\text { to drink more }\end{array}$ & 0.63 & 0.34 & 0.92 \\
\hline
\end{tabular}

Cl, confidence interval; LL, lower limit; UL, upper limit.

${ }^{1}$ One-way analysis of covariance.

${ }^{* * *} p<0.001$.

Chat lessons. No significant dose effect was identified between the number of lessons read and the willingness to suggest that a flushing classmate stop or reduce their drinking or to suggest to others that they should not pressure a flushing student to continue drinking.

\section{Analysis of Covariance}

One-way ANCOVA (Table 3) yielded a significant treatment effect on posttest willingness to intervene, after controlling for the pretest score, when the flusher was their classmate $(F[1,749]$, $13.16 ; p<0.001)$, when the flusher was a male $(F[1,749], 14.03$; $p<0.001)$, when the flusher was a female $(F[1,749], 28.65 ; p<$ 0.001 ), and when encouraging others not to pressure a flusher to drink more $(F[1,749], 17.92 ; p<0.001)$. The results also suggested that the posttest differences were related to the WeChat lessons.

\section{Learner Acceptance}

Of the 418 students in the intervention group, records on the number of lessons completed by each student were retrieved for 385 students: 61 (15.8\%) opened only lesson 1, 51 (13.2\%) opened lessons 1 and 2, and 273 (70.9\%) opened all 3 lessons. On a 10-point Likert scale ranging from "not very" (1) to "very" (10), the students' mean rating for "informative" was 7.00 (standard deviation [SD], 1.98), "interesting" 6.90 (SD, 1.98) and "useful" 6.30 (SD, 1.96).

\section{DISCUSSION}

This pilot study suggests that a brief WeChat-based alcoholrelated intervention program can be effective in changing undergraduate medical university students' willingness to suggest stopping or reducing drinking to fellow students whose deficient alcohol metabolism is evident through facial flushing. The lack of significant differences between those who completed the required tasks and those who did not, in both the intervention and the control groups, suggests that those who completed the program's basic requirements did not systematically differ from those who did not, and that the posttest differences were related to the WeChat lessons. Nevertheless, a larger proportion of the intervention group did not complete the posttest and were dropped from the analysis, compared to the control group, which introduces the possibility of selection bias.

This project confirmed how difficult it is to change cultural behaviors such as drinking patterns and how difficult it is to ensure the fidelity of an educational intervention that is managed solely by the learner.

There is a need to understand student motives in order to incorporate encouragement into a future program so that a higher proportion of students will complete a smartphone program about the risks of alcohol and flushing. Similarly, there is a need to apply more specifically what we know about behavior change in the design of the lessons and in the evaluation of the program. Research has suggested that behavioral change is more likely when there is a clear cognitive reason for the change, when the learner's level of self-efficacy related to 
the change is high, and when outcome expectancies for the desired behaviors are positive [20].

Based on a better understanding of user motives, lesson content, and behavior change, these lessons can be revised with more specific educational objectives. More specific educational objectives will provide a basis for a more sophisticated evaluation design, which would help evaluate individual lessons and their cumulative effects, enabling issues such as the dose effect to be evaluated.

The capability within WeChat to document measures such as how often students access the WeChat information and how much time they spend on each lesson should be used to the fullest extent. Future evaluation plans should allow participants to complete pretests and posttests online, rather than in classroom groups, as in this pilot study. WeChat messaging capabilities should be used to encourage students to read all the lessons and to complete the posttests.

\section{Limitations}

The brief intervention was carried out only in a single university with students in a single discipline: medicine. This was not a representative sample of university students. The sample was small and assigned to intervention and control groups by classroom, not individually. The difference in the proportion of students in the intervention group and the control group who completed both tests and were included in the analysis suggests the possibility of selection bias. Students' willingness to intervene was measured by hypothetical drinking situations. It is unknown how intentions would translate into actual behaviors in actual drinking situations. The variable "willingness to intervene" is vague. Variables such as behavioral intention, alcohol expectancy, and self-efficacy could more confidently correlate to actual behaviors. The follow-up time was 2 weeks, and this analysis did not investigate long-term effects.

\section{ACKNOWLEDGEMENTS}

Rui Zhang coordinated the project at the Medical University. Michelle Maas at the University of Nebraska-Lincoln provided editing assistance.

\section{CONFLICT OF INTEREST}

The authors have no conflicts of interest associated with the material presented in this paper.

\section{ORCID}

Lanyan Ding http://orcid.org/0000-0002-3037-5132

lan Newman http://orcid.org/0000-0002-4669-7064

\section{REFERENCES}

1. Zakhari S. Overview: how is alcohol metabolized by the body? Alcohol Res Health 2006;29(4):245-254.

2. Eng MY, Luczak SE, Wall TL. ALDH2, ADH1B, and ADH1C genotypes in Asians: a literature review. Alcohol Res Health 2007; 30(1):22-27.

3. Seitz HK, Becker P. Alcohol metabolism and cancer risk. Alcohol Res Health 2007;30(1):38-47.

4. Qian L, Newman IM, Yuen LW, Shell DF, Xu J. Variables associated with alcohol consumption and abstinence among young adults in central China. Int J Environ Res Public Health 2018; 15(8):E1675.

5. Newman IM, Shell DF, Huang Z, Qian L. The educational potential of alcohol-related flushing among Chinese young people. Drugs (Abingdon Engl) 2015;22(1):52-59.

6. Ding L, Yuen LW, Newman IM, Shell DF. University students' willingness to assist fellow students who experience alcoholrelated facial flushing to reduce their drinking. Int J Environ Res Public Health 2018;15(5):E850.

7. Newman IM, Jinnai I, Zhao J, Huang Z, Pu J, Qian L. Social meaning of alcohol-related flushing among university students in China. Asia Pac J Public Health 2013;25(5):409-419.

8. Newman IM, Ding L, Shell DF, Lin L. How social reactions to alcohol-related facial flushing are affected by gender, relationship, and drinking purposes: implications for education to reduce aerodigestive cancer risks. Int J Environ Res Public Health 2017;14(6):E622.

9. Poushter J. China outpaces India in internet access, smartphone ownership; 2017 Mar 16 [cited 2018 May 4]. Available from: http://www.pewresearch.org/fact-tank/2017/03/16/ china-outpaces-india-in-internet-access-smartphone-ownership/.

10. China Internet Network Information Center (CNNIC). Statistical report on internet development in China; 2017 [cited 2018 May 4]. Available from: https://cnnic.com.cn/IDR/ReportDownloads/201706/P020170608523740585924.pdf.

11. Baker DW, Dewalt DA, Schillinger D, Hawk V, Ruo B, BibbinsDomingo $\mathrm{K}$, et al. The effect of progressive, reinforcing telephone education and counseling versus brief educational in- 
tervention on knowledge, self-care behaviors and heart failure symptoms. J Card Fail 2011;17(10):789-796.

12. Rodgers A, Corbett T, Bramley D, Riddell T, Wills M, Lin RB, et al. Do u smoke after txt? Results of a randomised trial of smoking cessation using mobile phone text messaging. Tob Control 2005;14(4):255-261.

13. Gold J, Aitken CK, Dixon HG, Lim MS, Gouillou M, Spelman T, et al. A randomised controlled trial using mobile advertising to promote safer sex and sun safety to young people. Health Educ Res 2011;26(5):782-794.

14. Gajecki M, Berman AH, Sinadinovic K, Rosendahl I, Andersson C. Mobile phone brief intervention applications for risky alcohol use among university students: a randomized controlled study. Addict Sci Clin Pract 2014;9:11.

15. Nygaard P, Paschall MJ. Students' experiences with web-based alcohol prevention: a qualitative evaluation of AlcoholEdu. J Drug Educ 2012;42(2):137-158.
16. Carey KB, Scott-Sheldon LA, Garey L, Elliott JC, Carey MP. Alcohol interventions for mandated college students: a meta-anaIytic review. J Consult Clin Psychol 2016;84(7):619-632.

17. Shell DF, Newman M. Effects of a web-based pre-enrollment alcohol brief motivational intervention on college student retention and alcohol-related violations. J Am Coll Health 2018. doi: https://doi.org/10.1080/07448481.2018.1481072.

18. Fjeldsoe BS, Marshall AL, Miller YD. Behavior change interventions delivered by mobile telephone short-message service. Am J Prev Med 2009;36(2):165-173.

19. Hall AK, Cole-Lewis H, Bernhardt JM. Mobile text messaging for health: a systematic review of reviews. Annu Rev Public Health 2015;36:393-415.

20. Shell DF, Newman IM, Xiaoyi F. The influence of cultural orientation, alcohol expectancies and self-efficacy on adolescent drinking behavior in Beijing. Addiction 2010;105(9):16081615. 